\title{
Cardiac tamponade following traumatic rupture of a mediastinal mature teratoma
}

\author{
Jun-ichi Hirata, Munehiko Ohya
}

Department of Emergency and Critical Care Medicine, Kinki University Faculty of Medicine, Nara Hospital, Ikoma, Japan

\section{Correspondence to}

Dr Jun-ichi Hirata

qq-hira@hyo-med.ac.jp
To cite: Hirata J-ichi, Ohya M. BMJ Case Rep Published online: [please include Day Month Year] doi:10.1136/bcr-2013200176

\section{DESCRIPTION}

A 92-year-old woman was admitted to the emergency room owing to a history of lumbago after falling on her back during a walk. She had been
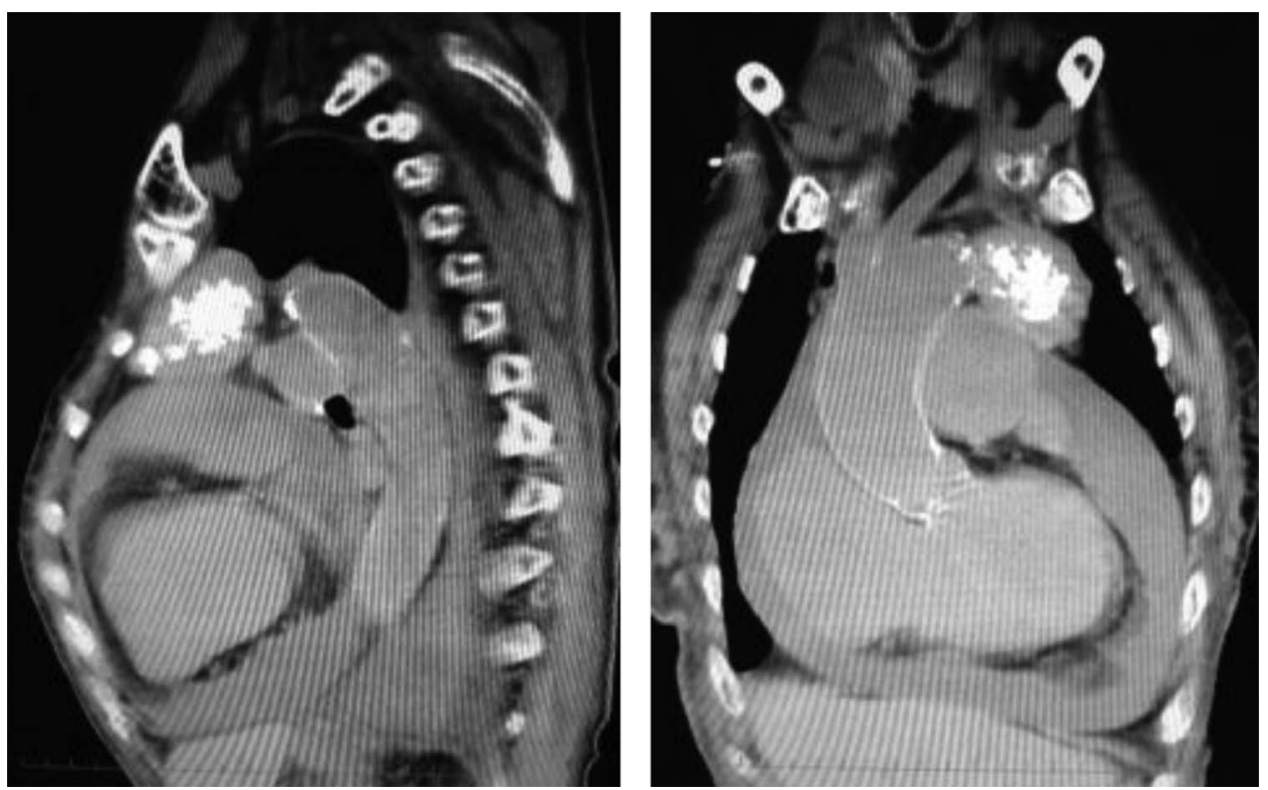

Figure 1 Thoracic CT obtained after the patient reported of the chest pain. Thoracic CT confirmed a well-defined anterior mediastinal heterogeneous mass $(5 \times 4 \times 6 \mathrm{~cm})$, bilateral pleural effusion and encysted massive pericardial effusion. The component density of pericardial and pleural effusion was lower than that of the blood.

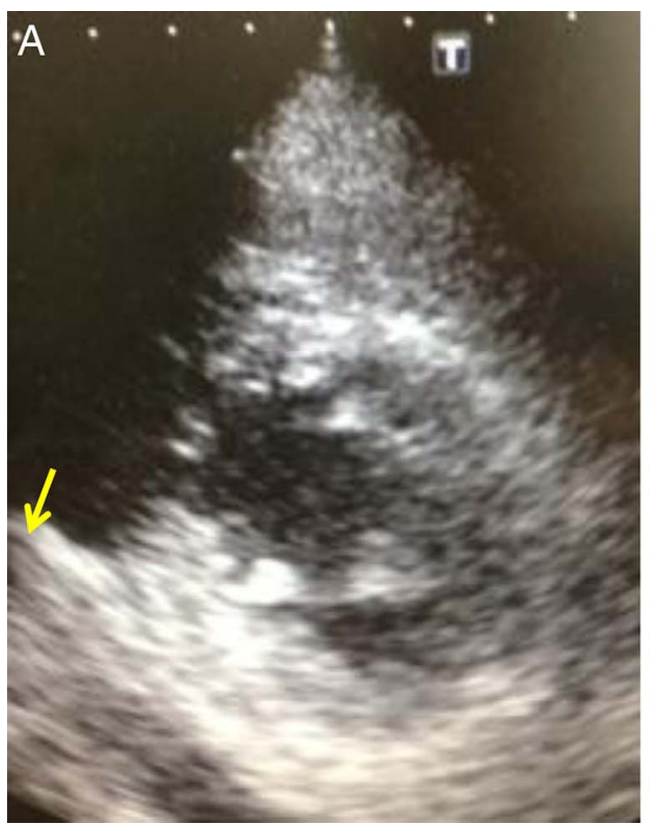

Figure 2 Echocardiograph features of before (A) and after (B) ruptured teratoma. (A)There were not any effusions in pericardial space at arrow 2 days prior to our emergency room presentation. (B) There were pericardial effusion at arrow and some fissures at circle in ruptured teratoma when she admitted to our emergency room.

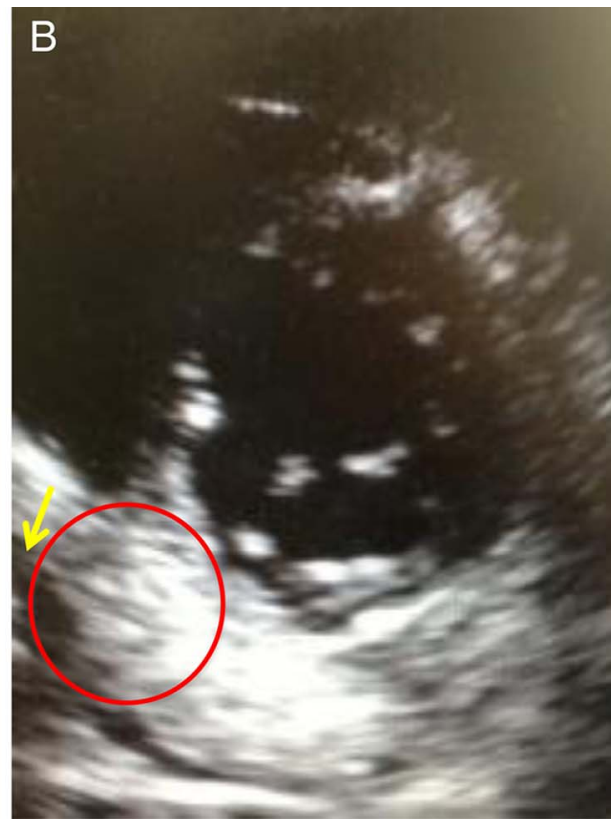

treated for mediastinal mature teratoma for the past 15 years. Thirty minutes after arriving at the emergency room, she reported chest pain, and a clinical examination revealed decreased blood pressure 
(from $140 / 79$ to $98 / 66 \mathrm{~mm} \mathrm{Hg}$ ) and an increased heart rate (from 88 to $107 \mathrm{bpm}$ ). A neck examination revealed jugular venous distention. Hence, the suspected diagnosis was a cardiac tamponade resulting from blunt traumatic thoracic aortic aneurysm rupturing into the pericardial sac. Initially, an echocardiography revealed a large global pericardial effusion, but no ischaemic change in the wall motion. A thoracic CT confirmed a well-defined anterior mediastinal heterogeneous mass $(5 \times 4 \times 6 \mathrm{~cm}$; figure 1$)$, bilateral pleural effusion and encysted massive pericardial effusion. However, component density in the pericardial and pleural effusion showed lower than blood. Thus, the anterior mediastinal mature teratoma rupturing into the pericardial sac was wrongly diagnosed as an aortic aneurysm. ${ }^{1}$ Further, an echocardiogram obtained 2 days previously did not reveal any ruptured teratoma (figure 2), and results of laboratory tests conducted the next day did not show progressive anaemia (haemoglobin $11.2 \mathrm{~g} / \mathrm{dL}$ and haematocrit 33.7\%). She refused pericardiocentesis, and she was administered with a diuretic for secondary congestive heart failure. The pericardial effusion reduced after 1 month. A traumatic ruptured teratoma is very rare $^{2}$; the goal of treatment is to prevent congestive heart failure, which should be used with attention to echocardiography.

\section{Learning points}

- The mechanisms involved in the rupture of mediastinal mature teratoma.

- Different phenomena leading to the rupture of mediastinal mature teratoma.

- Differential diagnosis of ruptured mediastinal mature teratoma in thoracic CT.

Contributors $\mathrm{J}-\mathrm{HH}$ was involved in the planning, execution and reporting of work. MO was also involved in the execution of work.

Competing interests None.

Patient consent Obtained.

Provenance and peer review Not commissioned; externally peer reviewed.

\section{REFERENCES}

1 Choi SJ, Lee JS, Song KS, et al. Mediastinal teratoma: CT differentiation of ruptured and unruptured tumors. AJR Am J Roentgenol 1998;171:591-4.

2 Sasaka K, Kurihara Y, Nakajima Y, et al. Spontaneous rupture: a complication of benign mature teratomas of the mediastinum. AJR Am J Roentgenol 1998; 170:323-8.

Copyright 2013 BMJ Publishing Group. All rights reserved. For permission to reuse any of this content visit

http://group.bmj.com/group/rights-licensing/permissions.

BMJ Case Report Fellows may re-use this article for personal use and teaching without any further permission.

Become a Fellow of BMJ Case Reports today and you can:

- Submit as many cases as you like

- Enjoy fast sympathetic peer review and rapid publication of accepted articles

- Access all the published articles

- Re-use any of the published material for personal use and teaching without further permission

For information on Institutional Fellowships contact consortiasales@bmjgroup.com

Visit casereports.bmj.com for more articles like this and to become a Fellow 